\title{
Pre-transplant Dementia is Associated with Poor Survival After Hematopoietic Stem Cell Transplantation: A Nationwide Cohort Study with Propensity Score Matched Control
}

\author{
Sheng-Min Wang ${ }^{1, *}$, Sung-Soo Park ${ }^{2, *}$, See Hyun Park ${ }^{3}$, Nak-Young Kim', Dong Woo Kang ${ }^{4}$, Hae-Ran Na , \\ Young-Yi Bae ${ }^{2}$, Jong Wook Lee ${ }^{2}$, Seunghoon Han ${ }^{3}$, Hyun Kook Lim ${ }^{1}$ \\ ${ }^{1}$ Department of Psychiatry, Yeouido St. Mary's Hospital, College of Medicine, The Catholic University of Korea, ${ }^{2}$ Department of Hematology, \\ Seoul St. Mary's Hospital, College of Medicine, The Catholic University of Korea, ${ }^{3}$ Department of Pharmacology, College of Medicine, The \\ Catholic University of Korea, ${ }^{4}$ Department of Psychiatry, Seoul St. Mary's Hospital, College of Medicine, The Catholic University of Korea, \\ Seoul, Korea
}

Objective: No previous study examined impact of dementia in the outcome of allogeneic hematopoietic stem cell transplantation (HSCT). We aimed to investigate overall survival (OS) of patients with dementia after receiving HSCT. Methods: Among 8,230 patients who underwent HSCT between 2002 and 2018, 5,533 patients younger than 50 years were first excluded. Remaining patients were divided into those who were and were not diagnosed with dementia before HSCT (dementia group: $\mathrm{n}=31$; no dementia: $\mathrm{n}=2,666$ ). Thereafter, among 2,666 participants without dementia, 93 patients were selected via propensity-matched score as non-dementia group. Patients were followed from the day they received HSCT to the occurrence of death or the last follow-up day (December 31, 2018), whichever came first. Results: With median follow-up of 621 days for dementia group and 654 days for non-dementia group, 2 year-OS of dementia group was lower than that of non-dementia group (53.3\% [95\% confidence interval, 95\% Cl, 59.0-80.2\%] vs. $68.8 \%$ [95\% Cl, 38.0-68.2\%], $p=0.076)$. In multivariate analysis, dementia had significant impacts on OS (hazard risk $=2.539,95 \% \mathrm{Cl}, 1.166-4.771, p=0.017)$.

Conclusion: Our results indicated that patients diagnosed with dementia before HSCT have 2.539 times higher risk of mortality after transplantation than those not having dementia. With number of elderly needing HSCT is increasing, further work to establish treatment guidelines for the management of HSCT in people with dementia is needed.

KEY WORDS: Dementia; Treatment; Survival; Hematopoietic stem cell transplantation.

\section{INTRODUCTION}

Allogeneic hematopoietic stem cell transplantation (HSCT) provides life-prolonging or curative therapy for

Received: June 16, 2020 / Revised: September 14, 2020

Accepted: October 26, 2020

Address for correspondence: Seunghoon Han

Department of Pharmacology, College of Medicine, The Catholic University of Korea, 222 Banpo-daero, Seocho-gu, Seoul 06591, Korea

E-mail: waystolove@catholic.ac.kr

ORCID: https://orcid.org/0000-0002-9976-5120

Hyun Kook Lim

Department of Psychiatry, Yeouido St. Mary's Hospital, College of Medicine, The Catholic University of Korea, 10 63-ro,

Yeongdeungpo-gu, Seoul 07345, Korea

E-mail:drblues@catholic.ac.kr

ORCID: https://orcid.org/0000-0001-8742-3409

*These authors contributed equally to this study as co-first authors. critical hematologic disorders, but it is a highly aggressive and demanding therapy with a significant risk of mortality $[1,2]$. Given the high transplant-related morbidity and mortality, HSCT was initially restricted to younger patients and was not indicated in patients older than 55 years of age [3]. However, incidence of most hematologic malignancies needing HSCT increases with age, and number of elderly needing HSCT have also increased with the aging of the population $[4,5]$. Moreover, recent advances in post-transplantation care and less toxic protocol such as reduced-intensity conditioning and nonmyeloablative conditioning regimens have expedited utilization of HSCT in elderly patients [6,7].

Numerous studies already demonstrated that HSCT is associated with worse neurocognitive performance $[8,9]$.

(c) This is an Open-Access article distributed under the terms of the Creative Commons Attribution Non-Commercial License (http://creativecommons.org/licenses/by-nc/4.0) which permits unrestricted non-commercial use, distribution, and reproduction in any medium, provided the original work is properly cited. 
It is generally known that large proportion of patients, ranging from $12-89 \%$, develop cognitive impairments even before receiving HSCT [10]. This risk is known to be particularly higher in elderly because chronic and malignant hematologic disorders and their treatments are speculated to accelerate cognitive aging $[11,12]$. Thus, joint recommendation of European and American groups specifically suggested that neurocognitive function should be assessed before and 1 year after HSCT [13] .

Neurocognitive dysfunction is suspected to have negative impacts in early and late post-HSCT course. Thus, it has emerged as a major cause for post-transplant morbidity and mortality [14]. Once cognitive decline persists and aggravates, it can progress to dementia which is characterized as cognitive decline accompanied with deterioration in behavior and the ability to perform everyday activities [15-17]. Despite this importance, most studies endeavored to clarify whether cognitive function improved, declined, or remained stable after HSCT. In contrast, to the best of our knowledge, no previous study has specifically examined impact of cognitive decline or dementia in the survival outcome after HSCT. Only one study showed that chemotherapy for acute myeloid leukemia had to be stopped in patients with dementia because of adverse effects such as behavioral and psychological symptoms of dementia (BPSD) [18]. However, among 31 patients only 7 patients had Alzheimer's disease, and the aim was to investigate clinical course of patients receiving chemotherapy rather than HSCT.
To fill this gap, we aimed to investigate treatment outcome of patients with neurocognitive dysfunction after receiving HSCT. Neurocognitive dysfunction covers wide range of clinical syndrome from subjective cognitive decline, mild cognitive impairment, and to dementia [19]. Among diverse conditions, dementia represents a more conservative and distinct group of patients identified with clinically significant cognitive decline along with functional disability due to cognitive dysfunction [20]. Considering its detrimental condition, number of patients with dementia receiving HSCT is scarce. Thus, we conducted a nationwide longitudinal cohort study and investigated impact of pre-transplant dementia in the survival outcome after HSCT.

\section{METHODS}

\section{Data Source}

This study used data from Korea National Health Insurance Sharing Service (KNHISS, https://nhiss.nhis.or.kr/bd/ab/ bdaba000eng.do). The Korean National Health Insurance Service (KNHIS), a compulsory public health insurance system of South Korea (hereafter "Korea"), provides universal coverage to all residents of Korea [21]. The KNHIS operates and manages KNHISS, in a form of National Health Information Database, which consists of healthcare data including health screening results, sociodemographic variables, and mortality for the whole Korean population. The data also contain all medical claims for

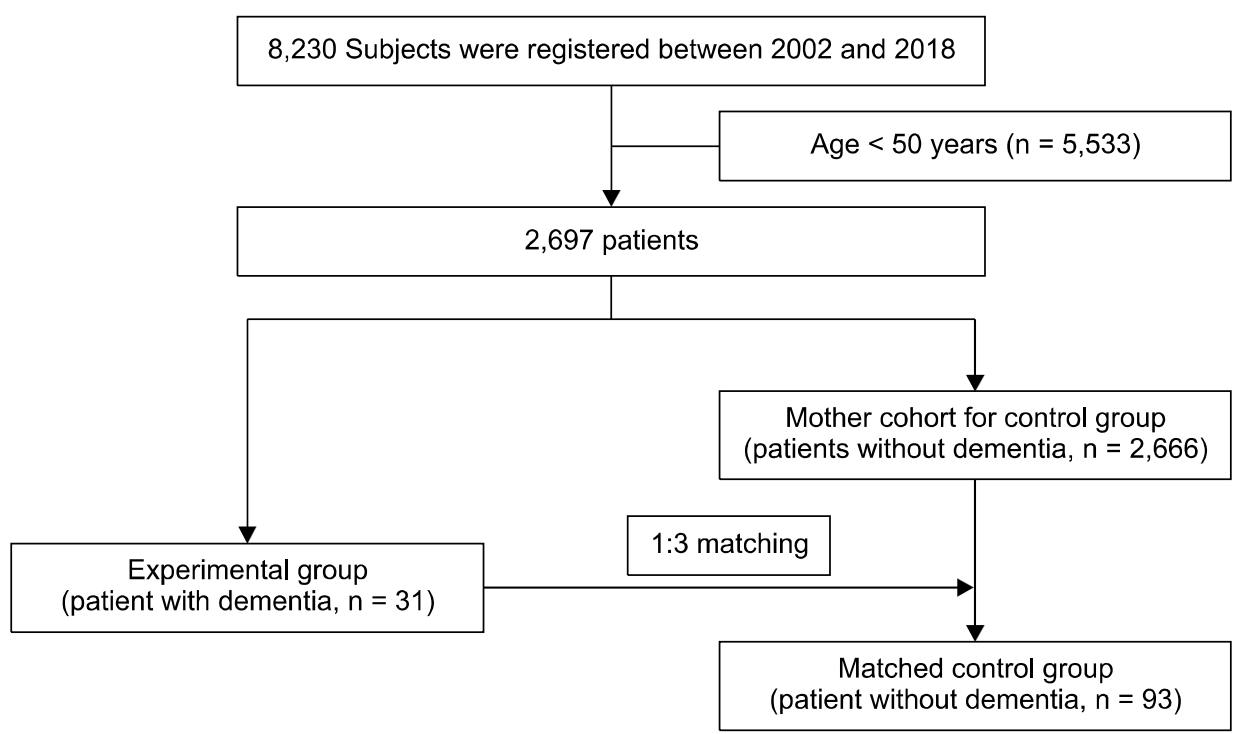

Fig. 1. Flow chart depicting creation of study cohorts. 
the population covered under the KNHIS. Thus, almost all HSCTs conducted in Korea are included in this database. The database has been widely used in various epidemiological studies and is described in detail elsewhere $[22,23]$.

\section{Study Cohort}

Patient selection for this study is summarized in Figure 1. We first identified a total of 8,230 patients who underwent HSCT between 2002 and 2018 using KNHIS database procedure codes X5061 for bone marrow and X5063 for peripheral blood HSCT. We first excluded 5,533 patients who were younger than 50 years. The remaining 2,697 patients were divided into those who were and were not diagnosed with dementia before HSCT (dementia group: $\mathrm{n}=$ 31; no dementia: $n=2,666)$. Thereafter, among 2,666 patients without dementia, 93 patients were selected as a matched control group (non-dementia group).

\section{Outcome Variable and Covariates}

The primary endpoint of this study was overall survival (OS) difference after HSCT according to pre-transplant de-

Table 1 . Baseline characteristics of patients after propensity score matching

\begin{tabular}{|c|c|c|c|}
\hline \multirow{2}{*}{ Variables } & \multicolumn{3}{|c|}{ Status of dementia } \\
\hline & Yes $(n=31)$ & No $(n=93)$ & $p$ value \\
\hline Median age at transplant (range, yr) & & & 0.946 \\
\hline $50-59$ & $11(35.5)$ & $32(34.4)$ & \\
\hline $60-69$ & $11(35.5)$ & $36(38.7)$ & \\
\hline$\geq 70$ & $9(29.0)$ & $25(26.9)$ & \\
\hline Sex & & & 0.999 \\
\hline Male & $12(38.7)$ & $38(40.9)$ & \\
\hline Hematologic disease & & & 0.917 \\
\hline Malignant hematology disease & $13(41.9)$ & $42(45.2)$ & \\
\hline Non-malignant hematology disease & $18(58.1)$ & $51(54.8)$ & \\
\hline Previous solid tumor & & & 0.999 \\
\hline No & $23(74.2)$ & $68(73.1)$ & \\
\hline Yes & $8(25.5)$ & $25(26.9)$ & \\
\hline Hypertension & & & 0.446 \\
\hline No & $13(41.9)$ & $30(32.3)$ & \\
\hline Yes & $18(58.1)$ & $63(67.7)$ & \\
\hline Diabetes & & & 0.916 \\
\hline No & $13(41.9)$ & $36(38.7)$ & \\
\hline Yes & $18(58.1)$ & $57(61.3)$ & \\
\hline Dyslipidemia & & & 0.628 \\
\hline No & $9(29.0)$ & $21(22.6)$ & \\
\hline Yes & $22(71.0)$ & $72(77.4)$ & \\
\hline Chronic obstructive pulmonary disease & & & 0.673 \\
\hline No & $28(90.3)$ & $88(94.6)$ & \\
\hline Yes & $3(9.7)$ & $5(5.4)$ & \\
\hline Cerebro- or cardiovascular disease & & & 0.999 \\
\hline No & $28(90.3)$ & $82(88.2)$ & \\
\hline Yes & $3(9.7)$ & $11(11.8)$ & \\
\hline Smoking & & & 0.459 \\
\hline No & $22(71.0)$ & $72(77.4)$ & \\
\hline Yes & $3(9.7)$ & $11(11.8)$ & \\
\hline Missing & $6(19.4)$ & $10(10.8)$ & \\
\hline Social income & & & 0.964 \\
\hline High & $13(41.9)$ & $40(43.0)$ & \\
\hline Intermediate & $5(16.1)$ & $18(19.4)$ & \\
\hline Intermediate to low & $6(19.4)$ & $13(14.0)$ & \\
\hline Low & $5(16.1)$ & $16(17.2)$ & \\
\hline Missing & $2(6.5)$ & $6(6.5)$ & \\
\hline
\end{tabular}

Values are presented as number (\%). 
mentia history. In order to utilize more conservative definition of dementia, patients who visited hospital due to International Classification of Diseases (ICD)-10 code of dementia (F00x, F01x, F02x, F03x, G30x, F051x, or G311x) were defined as having pre-transplant dementia. Demographic and clinical characteristics based on HSCT-specific comorbidity index [24], which are available at KNHIS database, such as age, sex, baseline hematologic disease, previous non-hematologic or solid tumor, hypertension, diabetes, dyslipidemia, chronic obstructive pulmonary disease, cerebro- or cardiovascular disease, smoking, and social income were included as covariates.

\section{Propensity Matching}

In order to account for non-random treatment allocation, we used propensity score to select matched patients among 2,666 patients who were not diagnosed with dementia before HSCT. Propensity score adjustment enables the researcher to account for comparability between groups by balancing the distribution of biases and confounders [25]. Thus, it is one of the strongest methods to balance measured covariates for groups before analysis [26].

We first collected baseline characteristics of all 31 patients from the dementia group based on HSCT-specific comorbidity index (Supplementary Table 1; available online) [24]. Thereafter, the propensity was estimated for each participant in the dementia group using a multivariate unconditional logistic regression model. Next, using nearest neighbor matching, each patient in the dementia group were paired with a patient from the non-dementia cohort with the closest propensity score [27]. Age, sex, baseline hematologic disease, previous non-hematologic or solid tumor, hypertension, diabetes, dyslipidemia, chronic obstructive pulmonary disease, cerebro- or cardiovascular disease, smoking, and social income were all included as covariates, and matching ratio was 1:3 for each dementia-non-dementia group pair yielded total of 93 patients in the non-dementia group. In terms of caliper width, which is allowable amount of deviation in scores among matches, we set it as 0 of the logit of the propensity score, which was possible because of large cohort size [28]

\section{Statistical Analysis}

Difference between the two groups (dementia group and non-dementia group) in baseline demographic and clinical characteristics were compared using Student's $t$ test for continuous and chi-squared test for categorical variables. Retrospective cohorts were followed from the day they received HSCT to the occurrence of death or the last follow-up day (December 31, 2018), whichever came first. The OS rate represents the proportion of patients who were alive at a certain time after the date of transplantation and was associated with death due to any cause. OS rates were calculated using the Kaplan-Meier method and compared using the log-rank test. Variables with $p<0.01$ in univariate analyses were entered into multivariate models with an exception for baseline age (50-59 years, 60-69 years, and above 70 years old). Finally, variables with $p<0.1$ and baseline age (regardless of its $p$ value) were included in multivariate Cox models of OS, using a backward stepwise model selection. For all statistical analysis, we used $\mathrm{R}$ statistical software (ver. 3.6.1; R Foundation for Statistical Computing, Vienna, Austria; 2019-07-05).

\section{RESULTS}

Details of clinical characteristics of each patient in dementia group are presented in Supplementary Table 1 (available online). There were 13 patients (41.9\%) who

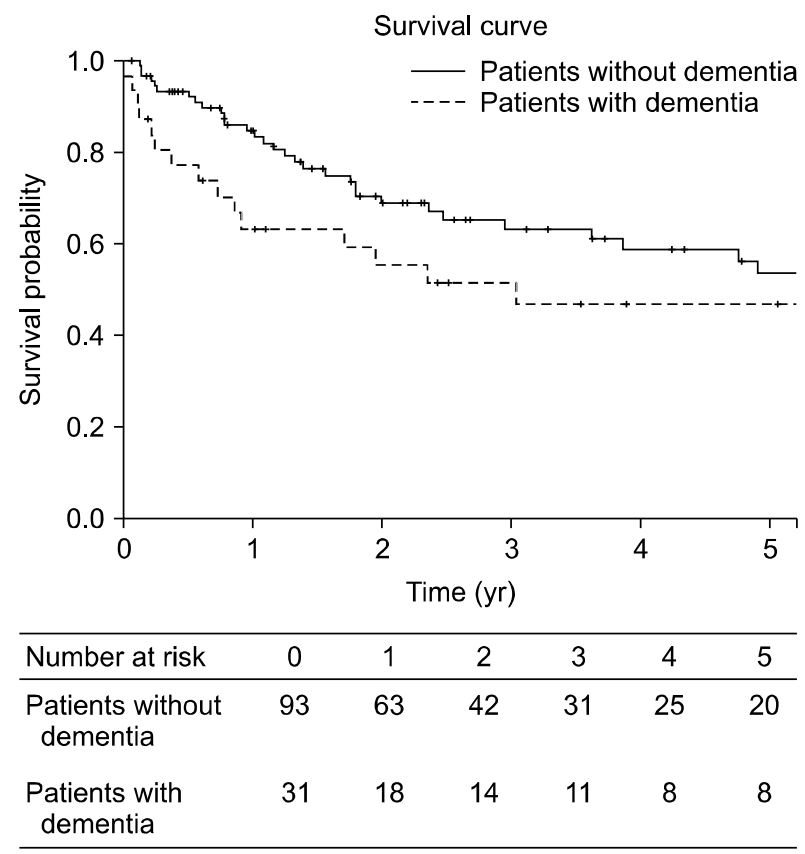

Fig. 2. Overall survival outcome difference between dementia and non-dementia group. 
received HSCT due to hematologic malignancies such as leukemia, lymphoma, multiple myeloma whereas 18 patients (58.1\%) received HSCT due to non-malignant hematologic disease including aplastic anemia and myelodysplastic syndrome. After matching propensity score of the dementia group with that of the non-dementia group, the baseline patient characteristics were comparable between dementia group and non-dementia group (Table 1). With median follow-up of 621 days (range, $1-3,733$ ) for dementia group and 654 days (range, 17-5,503) for non-dementia group, 2 year-OS of dementia group was lower than that of non-dementia group (53.3\% [95\% confidence interval, $95 \% \mathrm{Cl}, 59.0-80.2 \%$ ] vs. $68.8 \%$ [95\% Cl, 38.0-68.2\%], $p=0.076$ ] (Fig. 2).

Univariate analysis identified that sex, hematologic disease, dementia, and smoking status were potential factors associated with OS (Table 2). In multivariate analysis using potential variables derived from univariate analysis and age, we observed that dementia had significant impacts on OS (hazard risk $[\mathrm{HR}]=2.539,95 \% \mathrm{Cl}, 1.166-$ $4.771, p=0.017)$. Other factors including male $(\mathrm{HR}=$ $2.111,95 \% \mathrm{Cl}, 1.048-4.252, p=0.037)$ and malignant

Table 2. Univariate analysis of factors affecting overall survival of HSCT

\begin{tabular}{|c|c|c|c|}
\hline Variable & Patient $(n=124)$ & OS at 2 years $(95 \% \mathrm{Cl})$ & $p$ value \\
\hline Age (yr) & & & 0.399 \\
\hline $50-59$ & 43 & $64.0 \%(49.9-82.2 \%)$ & \\
\hline $60-69$ & 47 & $59.8 \%(45.9-78.0 \%)$ & \\
\hline$\geq 70$ & 34 & $74.2 \%(60.2-91.4 \%)$ & \\
\hline Sex & & & 0.007 \\
\hline Female & 74 & $76.5 \%(66.6-87.8 \%)$ & \\
\hline Male & 50 & $49.2 \%(36.0-67.2 \%)$ & \\
\hline Hematologic disease & & & 0.006 \\
\hline Non-malignant hematologic disease & 69 & $76.4 \%(66.2-88.2 \%)$ & \\
\hline Malignant hematologic disease & 55 & $50.9 \%(38.0-68.2 \%)$ & \\
\hline Dementia & & & 0.076 \\
\hline No & 93 & $68.8 \%(59.0-80.2 \%)$ & \\
\hline Yes & 31 & $55.3 \%(39.7-77.0 \%)$ & \\
\hline Previous solid tumor & & & 0.241 \\
\hline No & 91 & $68.7 \%(59.1-79.9 \%)$ & \\
\hline Yes & 33 & $54.6 \%(38.0-78.5 \%)$ & \\
\hline Hypertension & & & 0.242 \\
\hline No & 43 & $58.8 \%(44.5-77.7 \%)$ & \\
\hline Yes & 81 & $68.6 \%(58.4-80.6 \%)$ & \\
\hline Diabetes & & & 0.601 \\
\hline No & 49 & $68.7 \%(56.2-83.9 \%)$ & \\
\hline Yes & 75 & $62.7 \%(51.5-76.5 \%)$ & \\
\hline Dyslipidemia & & & 0.568 \\
\hline No & 30 & $67.3 \%(50.9-89.1 \%)$ & \\
\hline Yes & 94 & $64.8 \%(55.1-76.3 \%)$ & \\
\hline Chronic obstructive pulmonary disease & & & 0.503 \\
\hline No & 116 & $65.9 \%(57.1-76.1 \%)$ & \\
\hline Yes & 8 & $56.2 \%(28.1-100 \%)$ & \\
\hline Cerebro- or cardiovascular disease & & & 0.235 \\
\hline No & 110 & $68.1 \%(59.3-78.2 \%)$ & \\
\hline Yes & 14 & $39.3 \%(17.4-89.1 \%)$ & \\
\hline Smoking & & & 0.014 \\
\hline No & 94 & $67.3 \%(57.5-78.7 \%)$ & \\
\hline Yes & 14 & $34.1 \%(14.8-78.4 \%)$ & \\
\hline Missing & 16 & - & \\
\hline Social income & & & 0.526 \\
\hline High to intermediate & 76 & $69.2 \%(59.0-81.3 \%)$ & \\
\hline Intermediate-low to low & 40 & $57.6 \%(42.7-77.6 \%)$ & \\
\hline Missing & 8 & - & \\
\hline
\end{tabular}

$\mathrm{HSCT}$, allogeneic hematopoietic stem cell transplantation; OS, overall survival; $\mathrm{Cl}$, confidence interval; -, not available. 
Table 3. Multivariate analysis of factors affecting overall survival of HSCT

\begin{tabular}{|c|c|c|}
\hline Variable & Hazard ratio $(95 \% \mathrm{Cl})$ & $p$ value \\
\hline \multicolumn{3}{|l|}{ Age (yr) } \\
\hline $55-59$ & 1 & \\
\hline $60-69$ & $1.893(0.881-4.069)$ & 0.102 \\
\hline$\geq 70$ & $2.18(0.669-7.109)$ & 0.196 \\
\hline \multicolumn{3}{|l|}{ Sex } \\
\hline Female & 1 & \\
\hline Male & $2.111(1.048-4.252)$ & $0.037^{*}$ \\
\hline \multicolumn{3}{|l|}{ Hematologic disease } \\
\hline $\begin{array}{l}\text { Non-malignant hematologic } \\
\text { disease }\end{array}$ & 1 & \\
\hline $\begin{array}{l}\text { Malignant hematologic } \\
\text { disease }\end{array}$ & $2.493(1.044-5.959)$ & $0.040^{*}$ \\
\hline \multicolumn{3}{|l|}{ Dementia } \\
\hline No & 1 & \\
\hline Yes & $2.539(1.166-4.771)$ & $0.017^{*}$ \\
\hline \multicolumn{3}{|l|}{ Smoking } \\
\hline No & 1 & \\
\hline Yes & $1.927(0.826-4.5)$ & 0.129 \\
\hline
\end{tabular}

hematologic disease $(\mathrm{HR}=2.493,95 \% \mathrm{Cl}, 1.044-5.959$, $p=0.04$ ) were also significant factors associated with poor OS whereas smoking lost their statistical significances (Table 3).

\section{DISCUSSION}

To our knowledge, this is the first study examining the associations between pre-transplant dementia and survival outcome in patients receiving HSCT. We compared patients who were diagnosed with dementia before HSCT with those propensity score-matched patients and analyzed their survival outcome. Our study showed that patient diagnosed with dementia have 2.539 times higher risk of mortality. The hazard risk of malignant hematologic disease over non-malignant hematologic disease was found to be around 2.5 , which is in line with previous studies suggesting disease risk as $2.31-3.41$ [29]. In this perspective, we showed that the pre-transplantation dementia have similar negative impact on post-transplant survival with that of malignant hematologic disorders.

It is unclear how pre-HSCT dementia could affect mortality after transplantation. Patients with dementia have a shorter life expectancy than those without dementia $[30,31]$. A longitudinal study showed that patient with mild and moderate dementia have 2.23-3.10 times higher risk of mortality than those without dementia [32]. Thus, the higher post-transplantation mortality could be factors independent of HSCT such as dementia itself. Neurocognitive dysfunction is associated with more toxic pretransplant chemotherapy and severe disease state [33]. Thus, patients who developed dementia before HSCT might already had higher disease burden or worse general medical condition, which resulted in poor treatment outcome. Aggressive cytotoxic therapies are reported to exacerbate BPSD including delirium [18], which might have caused decrement in quality of life and survival rate [33]. Likewise dementia is known to decrease activities of daily living and performance status [34-36], which are important risk factors of post-HSCT morality [37]. In terms biochemical mechanism, immune dysregulation might be an important link [38]. Studies showed that it can take up to 2 years after HSCT for complete reconstitution of $\mathrm{CD}^{+}$ T cells [39]. Dementia is associated with the involution of the thymus, which result in a dramatic decrease in the production of new T cells $[40,41]$. Thus, patients with dementia might have higher risk of morbid infections. The immunological manifestation is more predominant in Alzheimer's disease, so this immunology hypothesis may not be directly applicable to other types of dementia. In the other perspective, patients with dementia including Alzheimer's disease, vascular dementia, and Lewy body disease are known to have increased risk of developing cerebrovascular and respiratory disease [42-44], which are two important negative prognostic factors of HSCT [24]. However, prospective studies investigating common pathway are needed to elucidate exact pathophysiological basis of association between pre-transplant dementia and post-HSCT mortality.

Interestingly, the longer-term survival (i.e., OS at 3 to 5-year) did not significantly differ between dementia group and non-dementia group. Once again, we can only speculate the reasons. First of all, after early treatment course, the risk from disease relapse and transplantationrelated mortality might have out-weighted that of dementia. Second, all patients included in our study were elderly. Thus, age-related comorbidity and mortality might also be an important contributing factor. Previous studies showed that people treated for cancer who have a pre-existing dementia tended to receive less necessary medical attention including later diagnosis and less treatment 
$[45,46]$. In this perspective, further work is needed to establish guidelines for the management of HSCT in people with dementia.

Our study has other strengths. Dementia is known to be associated with poor performance, so it is clinically difficult to undertake HSCT in patients with dementia. Finding and recruiting appropriate control and creating a study cohort is even more complicated. Despite this rarity and complexity, we were able to include 31 elderly patients who were diagnosed with dementia before HSCT. We conducted a nationwide cohort study and first included all patients who received HSCT from 2002 to 2018 and then selected patients who were diagnosed with dementia before transplantation. By doing so, we were also able to prevent selection bias and recruitment setting effect. We used propensity score matching via multivariate methods for control group creation, which is an advanced method in accounting for non-random allocation to transplant related mortality risk factors and the associated confounding variables [47]. This was possible only after a very careful characterization of the dementia cohort.

The limitation should also be noted when interpreting our findings. Dementia occurrence was based on clinical diagnosis with ICD-10 codes rather than on strict diagnosis using objective cognitive test results. In addition, we were unable to include biomarkers reflecting amyloid burden, tau pathology, and neuronal damage. Therefore, the diagnostic reliability might be an important issue. However, all 31 patients visited hospital due to ICD-10 codes for dementia. Regardless of diagnostic validity, our cohort represents patients having cognitive decline with functional abnormality, which is more than appropriate to investigate negative impact of cognitive dysfunction in survival outcome after HSCT. Other important risk factors such as type of pretransplant chemotherapy, details of procedures for HSCT including pretreatment process of HSCT, use of immuno-suppressive agents, and presence/ severity of GVHD were not included as part of covariates. In addition, infection before and after HSCT is one of the most important prognostic factors [24], but we were not able to include this in our analysis. Likewise, the cause of death and disease relapse according to dementia were not investigated. Additional prospective studies including above prognostic factors are needed to elucidate exact risk of dementia in survival after HSCT.

In conclusion, we showed that patients who were diag- nosed with dementia before HSCT have higher risk of mortality after transplantation than those not having dementia. In our cohort, the hazard risk of dementia was similar to that of malignant hematologic disease. Prospective studies are needed to confirm negative impact of dementia in HSCT outcome and to elaborate their pathophysiological basis. With number of elderly needing HSCT is increasing, further work to establish treatment guidelines for the management of HSCT in people with dementia is urgently needed.

\section{Acknowledgments}

This work was supported by the National Research Foundation of Korea (NRF) grant funded by the Korea government (MSIT) (NRF-2019R1C1C1011664).

\section{Conflicts of Interest}

No potential conflict of interest relevant to this article was reported.

\section{Author Contributions}

Designed the study, analyzed and interpreted data, and draft manuscript: Sheng-Min Wang, Sung-Soo Park, Seunghoon Han, Hyun Kook Lim. Project design, data collection, statistical analysis, and management: See Hyun Park. Project design, data management and manuscript revision: Nak-Young Kim, Dong Woo Kang, Hae-Ran Na, Jong Wook Lee, Young-Yi Bae. All authors have read and approved the revised manuscript.

\section{ORCID}

Sheng-Min Wang https://orcid.org/0000-0003-2521-1413 Sung-Soo Park https://orcid.org/0000-0002-8826-4136 See Hyun Park https://orcid.org/0000-0002-7278-7469 Nak-Young Kim https://orcid.org/0000-0003-0116-6283 Dong Woo Kang https://orcid.org/0000-0003-3289-075X Hae-Ran Na https://orcid.org/0000-0002-7960-8603 Young-Yi Bae https://orcid.org/0000-0001-5381-8648 Jong Wook Lee https://orcid.org/0000-0003-2949-4166 Seunghoon Han https://orcid.org/0000-0002-9976-5120 Hyun Kook Lim https://orcid.org/0000-0001-8742-3409

\section{REFERENCES}

1. Copelan EA, Chojecki A, Lazarus HM, Avalos BR. Allogeneic hematopoietic cell transplantation; the current renaissance. Blood Rev 2019;34:34-44. 
2. Majhail NS. Long-term complications after hematopoietic cell transplantation. Hematol Oncol Stem Cell Ther 2017;10: 220-227.

3. Wildes TM, Stirewalt DL, Medeiros B, Hurria A. Hematopoietic stem cell transplantation for hematologic malignancies in older adults: geriatric principles in the transplant clinic. J Natl Compr Canc Netw 2014; 12:128-136.

4. Weir HK, Thompson TD, Soman A, Møller B, Leadbetter S. The past, present, and future of cancer incidence in the United States: 1975 through 2020. Cancer 2015;121:18271837.

5. Jung KW, Won YJ, Oh CM, Kong HJ, Cho $\mathrm{H}$, Lee JK, et al. Prediction of cancer incidence and mortality in Korea, 2016. Cancer Res Treat 2016;48:451-457.

6. Hoogland AI, Nelson AM, Small BJ, Hyland KA, Gonzalez $\mathrm{BD}$, Booth-Jones $\mathrm{M}$, et al. The role of age in neurocognitive functioning among adult allogeneic hematopoietic cell transplant recipients. Biol Blood Marrow Transplant 2017;23: 1974-1979.

7. Gyurkocza B, Sandmaier BM. Conditioning regimens for hematopoietic cell transplantation: one size does not fit all. Blood 2014;124:344-353.

8. Mayo S, Messner HA, Rourke SB, Howell D, Victor JC, Kuruvilla J, et al. Relationship between neurocognitive functioning and medication management ability over the first 6 months following allogeneic stem cell transplantation. Bone Marrow Transplant 2016;51:841-847.

9. Scherwath A, Schirmer L, Kruse M, Ernst G, Eder M, Dinkel A, et al. Cognitive functioning in allogeneic hematopoietic stem cell transplantation recipients and its medical correlates: a prospective multicenter study. Psychooncology 2013;22: 1509-1516.

10. Phillips KM, McGinty HL, Cessna J, Asvat Y, Gonzalez B, Cases MG, et al. A systematic review and meta-analysis of changes in cognitive functioning in adults undergoing hematopoietic cell transplantation. Bone Marrow Transplant 2013; 48:1350-1357.

11. Ahles TA, Root JC, Ryan EL. Cancer-and cancer treatment-associated cognitive change: an update on the state of the science. J Clin Oncol 2012;30:3675-3686.

12. Mandelblatt JS, Hurria A, McDonald BC, Saykin AJ, Stern RA, VanMeter JW, et al.; Thinking and Living with Cancer Study. Cognitive effects of cancer and its treatments at the intersection of aging: what do we know; what do we need to know? Semin Oncol 2013;40:709-725.

13. Rizzo JD, Wingard JR, Tichelli A, Lee SJ, Van Lint MT, Burns $\mathrm{LJ}$, et al. Recommended screening and preventive practices for long-term survivors after hematopoietic cell transplantation: joint recommendations of the European Group for Blood and Marrow Transplantation, the Center for International Blood and Marrow Transplant Research, and the American Society of Blood and Marrow Transplantation. Biol Blood Marrow Transplant 2006;12:138-151.
14. Kelly DL, Buchbinder D, Duarte RF, Auletta JJ, Bhatt N, Byrne $\mathrm{M}$, et al. Neurocognitive dysfunction in hematopoietic cell transplant recipients: expert review from the late effects and Quality of Life Working Committee of the Center for International Blood and Marrow Transplant Research and complications and quality of life working party of the European Society for Blood and Marrow Transplantation. Biol Blood Marrow Transplant 2018;24:228-241.

15. Tarawneh R, Holtzman DM. The clinical problem of symptomatic Alzheimer disease and mild cognitive impairment. Cold Spring Harb Perspect Med 2012;2:a006148.

16. Hugo J, Ganguli M. Dementia and cognitive impairment: epidemiology, diagnosis, and treatment. Clin Geriatr Med 2014; 30:421-442.

17. Min EJ, Kim SG, Lee JS, Seo B, Jung WY, Huh SY, et al. Difference in cognitive function by first onset age of alcohol induced blackout and its duration. Clin Psychopharmacol Neurosci 2019;17:503-508.

18. Abe S, Kanaya K, Kikukawa M, Sakai M, Akai T, Takata Y, et al. Clinical results and issues of acute myeloid leukemia in elderly patients aged 75 years and older. Geriatr Gerontol Int 2011;11:290-296.

19. Cheng YW, Chen TF, Chiu MJ. From mild cognitive impairment to subjective cognitive decline: conceptual and methodological evolution. Neuropsychiatr Dis Treat 2017;13: 491-498.

20. Na R, Yang JH, Yeom Y, Kim YJ, Byun S, Kim K, et al. A systematic review and meta-analysis of nonpharmacological interventions for moderate to severe dementia. Psychiatry Investig 2019;16:325-335.

21. Song SO, Jung CH, Song YD, Park CY, Kwon HS, Cha BS, et al. Background and data configuration process of a nationwide population-based study using the Korean National Health Insurance system. Diabetes Metab J 2014;38:395-403.

22. Im GJ, Ahn JH, Lee JH, do Han K, Lee SH, Kim JS, et al. Prevalence of severe-profound hearing loss in South Korea: a nationwide population-based study to analyse a 10-year trend (2006-2015). Sci Rep 2018;8:9940.

23. Moon I, Lee SY, Kim HK, Han KD, Kwak S, Kim M, et al. Trends of the prevalence and incidence of hypertrophic cardiomyopathy in Korea: a nationwide population-based cohort study. PLoS One 2020;15:e0227012.

24. Sorror ML, Maris MB, Storb R, Baron F, Sandmaier BM, Maloney DG, et al. Hematopoietic cell transplantation (HCT)specific comorbidity index: a new tool for risk assessment before allogeneic HCT. Blood 2005; 106:2912-2919.

25. Baek S, Park SH, Won E, Park YR, Kim HJ. Propensity score matching: a conceptual review for radiology researchers. Korean J Radiol 2015; 16:286-296.

26. Gayat E, Resche-Rigon M, Mary JY, Porcher R. Propensity score applied to survival data analysis through proportional hazards models: a Monte Carlo study. Pharm Stat 2012;11: 222-229. 
27. Austin PC. A critical appraisal of propensity-score matching in the medical literature between 1996 and 2003. Stat Med 2008;27:2037-2049.

28. Austin PC. Optimal caliper widths for propensity-score matching when estimating differences in means and differences in proportions in observational studies. Pharm Stat 2011;10: 150-161.

29. Parimon T, Au DH, Martin PJ, Chien JW. A risk score for mortality after allogeneic hematopoietic cell transplantation. Ann Intern Med 2006; 144:407-414.

30. Gerritsen AAJ, Bakker C, Verhey FRJ, Pijnenburg YAL, Millenaar JK, de Vugt ME, et al. Survival and life-expectancy in a young-onset dementia cohort with six years of follow-up: the NeedYD-study. Int Psychogeriatr 2019;31:1781-1789.

31. Wolters FJ, Tinga LM, Dhana K, Koudstaal PJ, Hofman A, Bos $\mathrm{D}$, et al. Life expectancy with and without dementia: a population-based study of dementia burden and preventive potential. Am J Epidemiol 2019;188:372-381.

32. Villarejo A, Benito-León J, Trincado R, Posada IJ, PuertasMartín V, Boix R, et al. Dementia-associated mortality at thirteen years in the NEDICES cohort Study. J Alzheimers Dis 2011;26:543-551.

33. Hopkinson JB, Milton R, King A, Edwards D. People with dementia: what is known about their experience of cancer treatment and cancer treatment outcomes? A systematic review. Psychooncology 2016;25:1137-1146.

34. McManus RM, Heneka MT. Role of neuroinflammation in neurodegeneration: new insights. Alzheimers Res Ther 2017; 9:14.

35. Mishra BR, Sreeraj VS, Dhanashekaran S, Maiti R. Donepezil for compulsive behavior in degenerative dementia: case series. Clin Psychopharmacol Neurosci 2018;16:224-227.

36. Jung WS, Um YH, Kang DW, Lee CU, Woo YS, Bahk WM, et al. Diagnostic validity of an automated probabilistic tractography in amnestic mild cognitive impairment. Clin Psychopharmacol Neurosci 2018;16:144-152.

37. Artz AS, Pollyea DA, Kocherginsky M, Stock W, Rich E, Odenike $\mathrm{O}$, et al. Performance status and comorbidity predict transplant-related mortality after allogeneic hematopoietic cell transplantation. Biol Blood Marrow Transplant 2006;12: 954-964.
38. Grauer O, Wolff D, Bertz H, Greinix H, Kühl JS, Lawitschka A, et al. Neurological manifestations of chronic graft-versus-host disease after allogeneic haematopoietic stem cell transplantation: report from the Consensus Conference on Clinical Practice in chronic graft-versus-host disease. Brain 2010;133: 2852-2865.

39. Heining C, Spyridonidis A, Bernhardt E, Schulte-Mönting J, Behringer D, Grüllich C, et al. Lymphocyte reconstitution following allogeneic hematopoietic stem cell transplantation: a retrospective study including 148 patients. Bone Marrow Transplant 2007;39:613-622.

40. Guerriero F, Sgarlata C, Francis M, Maurizi N, Faragli A, Perna $\mathrm{S}$, et al. Neuroinflammation, immune system and Alzheimer disease: searching for the missing link. Aging Clin Exp Res 2017;29:821-831.

41. Cao W, Zheng H. Peripheral immune system in aging and Alzheimer's disease. Mol Neurodegener 2018;13:51.

42. Helmer C, Joly P, Letenneur L, Commenges D, Dartigues JF. Mortality with dementia: results from a French prospective community-based cohort. Am J Epidemiol 2001;154:642648.

43. Javanshiri K, Haglund M, Englund E. Cardiovascular disease, diabetes mellitus, and hypertension in Lewy body disease: a comparison with other dementia disorders. J Alzheimers Dis 2019;71:851-859.

44. Manabe T, Mizukami K, Akatsu H, Hashizume Y, Teramoto S, Nakamura S, et al. Prognostic factors related to dementia with Lewy bodies complicated with pneumonia: an autopsy study. Intern Med 2016;55:2771-2776.

45. Gorin SS, Heck JE, Albert S, Hershman D. Treatment for breast cancer in patients with Alzheimer's disease. J Am Geriatr Soc 2005;53:1897-1904.

46. Louwman WJ, Janssen-Heijnen ML, Houterman S, Voogd AC, van der Sangen MJ, Nieuwenhuijzen GA, et al. Less extensive treatment and inferior prognosis for breast cancer patient with comorbidity: a population-based study. Eur J Cancer 2005; 41:779-785.

47. Velentgas PT, Dreyer NA, Nourjah P, Smith SR, Torchia M. Developing a protocol for observational comparative effectiveness research: a user's guide. Rockville:Agency for Healthcare Research and Quality;2013. 